УДК 614.875+371.71+612.821

\title{
ЦИФРОВИЗАЦИЯ, ДИСТАНЦИОННОЕ ОБУЧЕНИЕ И АСПЕКТЫ ЭЛЕКТРОМАГНИТНОЙ БЕЗОПАСНОСТИ СОВРЕМЕННОГО ОБРАЗОВАНИЯ
}

\author{
Хорсева Наталия Игоревна \\ кандидат биологических наук, \\ старший научный сотрудник \\ Институт биохимической физики \\ им. Н.М. Эмануэля РАН \\ Институт космических исследований РАН \\ Марахова Виктория Александровна \\ зам. директора по УВР, педагог-психолог \\ высшей квалификационной категории \\ Государственное автономное образовательное \\ учреждение «Химкинский лицей»
}

Аннотация: В статье рассмотрены вопросы нормирования воздействия электронных средств обучения, электромагнитной безопасности для детей и подростков в рамках цифровизации образования и дистанционной формы обучения. Приведены данные собственных исследований: изменения психофизического здоровья обучающихся при дистанционной форме обучения, а также результаты профилактической работы по формированию культуры использования современных гаджетов.

Ключевые слова: цифровизация, дистанционное обучение, нормативные акты, здоровье, обучающиеся.

\section{DIGITALIZATION, DISTANCE LEARNING AND ASPECTS OF ELECTROMAGNETIC SAFETY OF MODERN EDUCATION}

\section{Khorseva Natalia Igorevna Marakhova Victoria Alexandrovna}

\footnotetext{
Abstract: The article deals with the issues of regulation of the impact of electronic teaching aids, electromagnetic safety for children and adolescents in the 
framework of digitalization of education and distance learning. The data of our own research are presented: changes in the psychophysical health of students in the distant form of education, as well as the results of preventive work on the formation of a culture of using modern gadgets.

Key words: digitalization, distance learning, regulations, health, students.

Стремительное развитие цифровых технологий в сфере образования диктуется сложившейся современной реальностью, о чем 1 марта 2018 года подчеркивал В.В. Путин в послании Федеральному Собранию [1], а с 2019 года трансформировалось в федеральный проект «Цифровая образовательная среда».

Процесс цифровизации - действие не одного дня и требует качественного обновления существующей практики педагогических исследований, превращения их в инструмент научно-методического обеспечения и поддержки процессов цифровой трансформации образования [2]. Этот процесс невозможен без деятельного участия учащихся, педагогов, родителей, работников управления.

Однако сама цифровизация образования опирается на использование различных информационных технологий, предусматривающих использование электронных средств обучения (ЭСО), что затрагивает область безопасности их использования в образовательном процессе, поскольку все они являются источниками электромагнитного излучения.

Безусловно, современные гаджеты прочно вошли в обиход повседневной жизни, но и при всех их преимуществах они является открытыми и неконтролируемыми источниками электромагнитного излучения. И, следовательно, могут оказывать влияние на организм человека и в первую очередь, нашего подрастающего поколения.

Можно считать доказанным, что воздействие электромагнитного излучения затрагивает все уровни организации - от молекулярного до влияния на целый организм. Выявленные негативные последствия весьма разнообразны по биологическим эффектам. Это значит, что в зоне риска особенно находится подрастающее поколение - как активные пользователи различных гаджетов (в том числе и в стенах образовательных учреждений), поскольку, в отличие от организма взрослых, формирующийся, растущий организм весьма чувствителен к воздействию ЛЮБЫХ факторов окружающей среды. 
Многочисленные исследования российских и зарубежных ученых, рассматривающие вопросы использования целой когорты современных гаджетов и устройств, бесспорно ДОКАЗАЛИ, что их НЕКОНТРОЛИРУЕМОЕ использование может приводить как к соматическим расстройствам, так и к психологическим отклонениям.

В частности, уже состоявшийся факт, что мобильная связь также стала неотъемлемой частью существования цивилизации. И уже как-то на второй план ушло сообщение Международного агентства по исследованию рака (IARC), которое отнесло электромагнитное излучение (ЭМИ) мобильных телефонов (MT) к категории 2B - потенциально опасных и приводящих к развитию рака головного мозга. А если учесть, что при использовании МТ чаще всего подносят к голове, то мы имеем непосредственное воздействие ЭМИ на структуры головного мозга и в этом случае наши дети входят сейчас в ОСНОВНУЮ, ГРУППУ РИСКА. И, несмотря на то, что в новых СанПинах в России (СП 2.4.3648-20) запрещено использовать мобильные телефоны в образовательных целях, пользование данными гаджетами происходит у обучающихся на переменах и вне школьных занятий, в том числе для поиска необходимой информации в Интернете.

Тем не менее, в настоящий момент нами получены убедительные доказательства того, что ВСЕ психофизиологические показатели у детей пользователей мобильной связью ухудшаются. Это утверждение основывается на наших многолетних мониторинговых исследованиях целого комплекса психофизиологических показателей детей-пользователей мобильной связью $[3,4]$ которое реализуется на базе ГАОУ МО «Химкинский лицей» (базовой школе РАН). Практические результаты неоднократно докладывались на международных и российских конгрессах и конференция [5-11].

Следует отметить, что на фоне профилактических мер, которые проводятся в Химкинском лицее, увеличилось число учащихся, использующих безопасный режим пользования МТ [12].

Таким образом, целенаправленная и постоянно действующая система профилактической работы в образовательном учреждении, учитывающая все уровни взаимодействия и включающая в себя разнообразные формы деятельности, эффективно позволяет формировать культуру пользования МТ среди участников образовательного процесса. 
Нельзя не отметить и уникальные исследования коллег из Белоруссии, доказывающие негативное влияние на репродуктивную систему человека это книга Верещако Геннадия Григорьевича [13] и диссертационная работа Чуешовой Натальи Владимировны [14].

Результаты этих исследований в первую очередь особо актуальны для лиц мужского пола, которые предпочитают носить мобильные телефона в карманах брюк. Это объясняется тем, что в этом случае электромагнитное излучение направленно воздействует на органы малого таза, включая репродуктивную систему.

Практически аналогичные результаты были получены для случаев, когда пользователи, при использовании компьютеров и планшетов с подключенным Wi-Fi, держа его на коленях [15]. Действительно, наши дети очень часто, при пользовании ноутбуками и планшетами держат их на коленях. В этом случае данная поза не только негативно влияет на осанку, но и подвергает мошонку не только тепловому воздействию от нагревающихся элементов самого гаджета, но и электромагнитного излучения беспроводной сети Wi-Fi.

Но особое внимание в рамках цифровизации образования следует обратить внимание на использование дистанционной формы обучения. В настоящее время в научной литературе идут бурные дискуссии о дистанционном образовании, которые указывают порой на неоднозначность и спорность некоторых заявлений о бесспорном его преимуществе над традиционным [16].

Опуская вопросы нормативно-правовой базы использования дистанционного обучения, преимущества и недостатков данной технологии, в первую очередь надо рассматривать данную проблему с точки зрения безопасности её использования для обучающихся. Однако в большинстве работ рассматриваются вопросы технического обеспечения, правовой базы и прочих условий осуществления дистанционного обучения, практически не учитываются возможные негативные последствия для здоровья участников образовательного процесса. В данном случае следует обратить внимание на исследование, проведенное целым коллективом ученых-медиков под руководством Кучмы В.Р в период пандемии. Был проведен анонимный опрос с использованием онлайн-конструктора Google Forms 29779 обучающихся 5-11-х классов из 79 регионов России в период 27 апреля - 26 мая 2020 [17]. Было установлено, что значительно возросшие продолжительность 
«школьных учебных занятий» и выполнения домашних заданий сопровождалось одновременным увеличением времени работы электронными устройствами и гаджетами. Выявлены соматические нарушения: отмечены признаки компьютерного зрительного синдрома, отмечены неблагополучные психические реакции пограничного уровня. Авторы подчеркивают, что «...в период эпидемии COVID-19 отсутствовало должное медико-психологопедагогическое сопровождение детей и родителей, что указывает на необходимость гигиенического регламентирования дистанционного обучения и разработки программы действий в подобных условиях с целью снижения риска нарушения здоровья всех участников образовательного процесса в условиях самоизоляции и дистанционного обучения» [цит. по 17].

Имея в своем распоряжении данные наших мониторинговых наблюдений динамики психофизиологических показателей учащихся, проводимых в Химкинском Лицее уже седьмой год, было проведено сравнение показателей при очном и дистанционном обучении. Необходимо сразу отметить, что, в отличие от исследований Кучмы B.P. с соавторами, которое было осуществлено в период пандемии, диагностика была проведена в период ноябрь 2020 по апрель 2021 года (1-5 классы). Таким образом, полученные нами результаты можно рассматривать как отдаленные последствия дистанционного обучения. Результатов показателей произвольного внимания (точность и продуктивность) и смысловой памяти (точность и время выполнения задания) после дистанционного обучения в прошлом году (257 учащихся 2-5 классов) сравнивались с результатами предыдущих лет при очном обучении (1267 учащихся 2-5 классов). Следует особо подчеркнуть, что диагностика учащихся 5-х классов, начального звена как в 2020/2021 учебном году, так и в предыдущие годы проводилась в один и тот же период - ноябрь-декабрь (5 классы) и январь-апрель (начальное звено). Кроме того, результаты диагностики после дистанционного обучения для учащихся начальной школы получены на фоне периода очного обучения в первом полугодии.

Анализ показателей произвольного внимания и смысловой памяти показал, что статистически значимые различия отсутствуют. Тем не менее, дополнительный анализ абсолютных значений для группы учащихся после дистанционного обучения, выявил следующее: по уровню сформированности когнитивных процессов (произвольного внимания и смысловой памяти) увеличилось число учащихся так называемой «группы риска» - учащиеся, у 
которых явный дисбаланс показателей (два и более показателей ниже возрастной нормы). В первую очередь это относится к показателям продуктивности произвольного внимания и времени выполнения задания «смысловая память» (оно возрастало). В целом по всей группе учащихся 2-5 классов после дистанционного обучения колебание процента числа учащихся, отнесенных к «группе риска» составил от 7,7\% до 31,3\% учащихся, тогда как при очном обучении данный показатель был в пределах 6,5\%-10,7\%.

Увеличилась востребованность специалистов медико-социального профиля: офтальмолога с 9,2-11,5\% до 14,6\%, при этом увеличилось и число учащихся, которые стали носить очки после дистанта - с 5,3-7,9\% при очном обучении - до 4,0-13,4\% после дистанционного обучения; консультации психолога - с 1,6-2,5\% до 10,4\%.

Мы полагаем, что ещё одним немаловажным фактором, который повлиял на ухудшение, в частности, когнитивных показателей, является изменение системы формирования универсальных учебных действий ежедневной направленности на фоне отсутствия четкого образовательного режима в рамках дистанционного обучения $[18,19]$.

Таким образом, цифровизация образования, внедрение новых технологий с использованием электронных средств обучения должны иметь под собой не только научно обоснованную базу их использования, но и медико-социальный контроль за их использованием.

В этой связи необходимо рассмотреть вопросы нормирования использования электронными средствами обучения.

Отметим, что с конца прошлого века состоялись различные комиссии, приняты многочисленные решения в области принятия необходимых мер по уменьшению негативного воздействия ЭМИ современных гаджетов (в первую очередь мобильного телефона - МТ) на организм детей и подростков, они используются при полном отсутствии четких, научно обоснованных гигиенических норм их применения.

В 2003 году в России были приняты два СанПина по регламенту использования мобильной связи (СанПиН 2.1.8/2.2.4.1190-03) и электронновычислительной техники (СанПиН 2.2.2/2.4.1340-03). Но в первом случае использование МТ ограничилось практически одним пунктом, а во втором при достаточно подробном нормировании работы с ЭВМ, включая дополнительные занятия, ОТСУТСТВУЮТ данные о максимально 
допустимом ежедневном времени пользования с учетом использования их в домашних условиях.

Спустя 16 лет, 14 августа 2019 года вышли «Методические рекомендации об использовании устройств мобильной связи в общеобразовательных организациях», утвержденные руководителями Федеральной службы по надзору в сфере защиты прав потребителей и благополучия человека (№ MP 2.4.0150-19) и Федеральной службы по надзору в сфере образования и науки (№ 01-230/13-01). 10 января 2020 года на сайте Роспотребнадзора Российской Федерации опубликованы рекомендации родителям по безопасному использованию мобильного телефона.

В этих рекомендация на государственном уровне было подтверждено, что дети находятся в группе риска. Уже хорошо, что государственные структуры России обратили внимание на проблему негативного влияния излучения мобильных телефонов на организм подрастающего поколения. Однако в данном документе есть исключительно общие фразы, раскрывающие общую проблему и основные направления организации неких профилактических мероприятий по снижению негативного воздействия излучения МТ на организм детей и подростков в условиях образовательного учреждения.

И, наконец, в 2020 году на сайте НИИ гигиены и охраны здоровья детей и подростков ФГАУ НМИЦ Здоровья Детей Минздрава России представлены «Гигиенические нормативы и специальные требования к устройству, содержанию и режимам работы в условиях Цифровой образовательной среды в сфере общего образования» [20]. К сожалению, анализ материалов, изложенных в данных нормативах вызывает много вопросов, в первую очередь с точки зрения нормирования использования электронных средств обучения с учетом электромагнитной безопасности.

Так, нормирование ЭСО (интерактивных досок, планшетов, компьютеров, ноутбуков, планшетов) очень подробно расписаны технические характеристики их использования (расстояние от..., цвет экрана, шрифты и пр), а вот электромагнитная «нагрузка» использования -позиция, к которому много вопросов. Ранее в СанПинах 2003, 2010 (СанПин 2.4.2.2821-10 https://rg.ru/2011/03/16/sanpin-dok.html) с дополнениями в 2015 (СанПин 2.4.2.2821-10 новая редакция от 24.11.2015 N 81 http:/docs.cntd.ru/ document/420324427) отсутствуют нормы по временному использованию ЭСО в день, с учетом их использования дома. НО если сравнить даже те ранее 
принятые временные нагрузки по использованию. ЭСО, то нетрудно заметить, что предлагаемые временные «нормы» в документе 2020 намного выше, чем в предыдущих гигиенических нормативах.

15 сентября 2020 года состоялось расширенное заседание рабочей группы по вопросам защиты прав детей и подростков на образование, воспитание и всестороннее развитие Общественного совета при Уполномоченном при Президенте Российской федерации по правам ребенка, где поднимался вопрос в том числе нормирования использования электронных средств обучения (https://youtu.be/yuVrMBvouGE)

Тем не менее, в конце 2020 года и начале 2021 года вышли две новые редакции СанПинов, которые отменяли все предыдущие. СП 2.4. 3648-20 "Санитарно-эпидемиологические требования к организациям воспитания и обучения, отдыха и оздоровления детей и молодежи» [21] и СанПиН 1.2.368521 «Гигиенические нормативы и требования к обеспечению безопасности и (или) безвредности для человека факторов внешней среды обитания» [22].

В СП 2.4. 3648-20 в разделе «Общие требования» п. 2.10 .2 описан регламент работы с ЭСО на уроке и указано, что ЭСО должны соответствовать гигиеническим нормативам. Существующие гигиенические нормативы касаются диагонали экрана, шрифтовому оформлению учебного материала, расстоянию до экрана при пользовании ЭСО и пр. НО ни слова об электромагнитной нагрузке, которая может потенциально давать то или иное ЭСО (такие характеристики отсутствуют и во всех технических описаниях).

В п. 3.5 описаны условия использования ЭСО, но без временных рамок. Кроме того, практически одной строкой в п 3.5 .3 отмечено, что «для образовательных целей мобильные средства связи не используются. Размещение базовых станций подвижной сотовой связи на собственной территории образовательных организаций не допускается». Однако зачастую вышка появляется непосредственно около образовательного учреждения, но за забором(!).

В СанПиН 1.2.3685-21 «Гигиенические нормативы и требования к обеспечению безопасности и (или) безвредности для человека факторов внешней среды обитания», в разделе V Физические факторы (за исключением ионизирующего излучения) единственные параметры, описывающие предельно допустимые уровни электрических и магнитных полей промышленной частоты 50 Гц, в том числе и для детских, дошкольных, 
школьных и общеобразовательных учреждений описаны в таблице 5.41, а предельно допустимые уровни электромагнитных полей (ЭМП) (без указаний на принадлежность помещений) диапазона частот 30 кГц-300ГГц - в таблице 5.42 (10 мкВт/см2). Далее в п. 124 изложены расчеты предельно допустимых уровней (ПДУ) при воздействии от нескольких источников ЭМП, а в п. 125 допустимые уровни ЭМП... у головы пользователя (в диапазоне частот

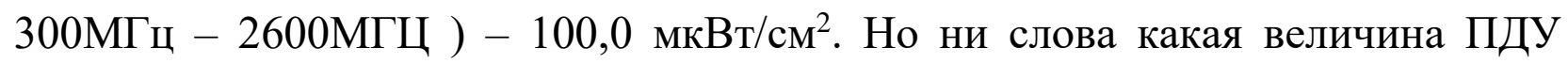
допустима для детей и подростков. Получается, те же 100,0 мкВт/см². Но на чем основываются даже эти нормативы? На одной единственной работе Н.Б.Рубцоой, опубликованной в 2006 году [23], где было указано, что, опираясь на экспериментальные исследования, проведенные на 25 добровольцах после ОДНОКРАТНОГО воздействия ЭМП от аппаратов мобильной связи различных моделей сотовых телефонов и на 110 крысах (хроническое воздействие) был установлен показатель в 100,0 мкВт/см2 как наименьшая интенсивность, которая вызывает биологические эффекты. Авторы указывают, что это значение в качестве временного допустимого уровня в нормативно-методическом документе СанПиН 2.1.8/2.2.4.1190-03. Но временный показатель существует до сих пор и благополучно перекочевал без всяких изменений из СанПиН 2.1.8/2.2.4.1190-03 в СанПиН 1.2.3685-21.

Далее, в разделе VI Гигиенические нормативы по устройству, содержанию и режиму работы организаций воспитания и обучения, отдыха и оздоровления детей и молодежи в п. 186-189 описаны общие вопросы использования ЭСО в образовательном процессе, а в таблице 6.8 приведены данные по рекомендуемой продолжительности использования ЭСО, в том числе «суммарно в день в школе» и «суммарно в день дома (включая досуговую деятельность)».

Однако к данным документам возникает немало вопросов. Почему данные по использованию ЭСО на уроках проведены в СП 2.4. 3648-20, а длительность их использования в день - в СанПиН 1.2.3685-21. Почему временные нормативы ПДУ воздействия ЭМП от аппаратов сотовой связи не только не изменился за 18 лет, но и не учитывает новый контингент пользователей - детей и подростков. А бо́льшая чувствительность детского организма к любым воздействиям факторов внешней среды в том числе и в период внутриутробного развития (WHO, Backgrounder № 3, 2003), требует и новых нормативных границ. Далее, на чем основываются нормативы 
использования ЭСО, и на каких исследованиях основывается предложенный регламент.

Еще большее недоумение вызывают позиции, касающиеся использования беспроводной связи и мобильных телефонов/смартфонов в образовательном процессе. Использование Wi-Fi в образовательных учреждениях уже запрещено в Бельгии, Испании, Израиле, Австралии, Италии, Швейцарии, Германии, Австрии, Индии, Финляндии, Кипре, Греции и др. Тем не менее, авторы Руководства «Гигиенические нормативы и специальные требования к устройству, содержанию и режимам работы в условиях Цифровой образовательной среды в сфере общего образования», опубликованном на сайте НИИ гигиены и охраны здоровья детей и подростков ФГАУ НМИЦ [24] указывают, что применение беспроводных технологий не допускается в начальной школе. Тогда как объяснить проект совместного документа Минпросвещения России и Минцифры России «об утверждении стандарта «цифровая школа» [25]. Wi-Fi сети должны охватывать практически ВСЕ помещения образовательного учреждения. А как же нормативы их использования? В интервью Ирины Викторовны Брагиной, заместителя руководителя Федеральной службы по надзору в сфере защиты прав потребителей и благополучия человека, было сказано, что сети Wi-Fi в образовательных учреждениях «не относятся к подвижной сотовой связи, поэтому оно не запрещено». А как же электромагнитное излучение, которое будет воздействовать на учащихся в период обучения?

Мы полагаем, что сложившаяся ситуация требует уже кардинального решения: требуется разработка ОТДЕЛЬНОГО СанПина для всех имеющихся современных низкоинтенсивных источников электромагнитного излучения, включая $\mathrm{Wi}$ - Fi и новый стандарт - 5G, с научно-обоснованными нормативами и четкими регламентами их использования нашим подрастающим поколением, что позволит не только использовать разнообразные блага современного прогресса (в том числе в сфере образования), но и сохранить здоровье детского населения. 


\section{Список литературы}

1. Послание Президента Федеральному Собранию 1 марта 2018 года

2. Уваров А.Ю., Гейбл Э., Дворецкая И. В. и др. Трудности и перспективы цифровой трансформации образования - М.: Изд. дом Высшей школы экономики, 2019. - 343с.

3. Григорьев Ю.Г., Хорсева Н.И. Мобильная связь и здоровье детей. Оценка опасности применения мобильной связи детьми и подростками. Рекомендации детям и родителям М.: Экономика, -2014. -230 с.

4. Grigoriev Y.G., Khorseva N.I. Chapter 10. A Longitudinal Study of Psychophysiological Indicators in Pupils Users of Mobile Communications in Russia (2006-2017): Children Are in the Group of Risk. Mobile Communications and Public Health /Edited by Marko Markov / 2019 by Taylor \& Francis Group, LLC CRC Press is an imprint of Taylor \& Francis Group, an Informa business $p$ 237-253.

5. Хорсева Н.И. Григорьев Ю.Г., Григорьев П.Е. Мобильные телефоны. Психофизиологические показатели детей и подростков через призму современных гаджетов // «Радиобиология: актуальные проблемы»: материалы международной научной конференции 27-28 сентября 2018 года Гомель, Республика Беларусь.- Минск, - 2018.- С. 167-169

6. Хорсева Н.И., Григорьев Ю.Г. Прогресс мобильной связи и здоровье подрастающего поколения. ситуация требует решения //Радиобиология: современные проблемы 2020: материалы международной научной конференции ( Гомель, 24 - 25 сентября 2020 г) - Минск, - 2020. - С. 138-142.

7. Хорсева Н.И., Григорьев Ю.Г. Здоровье детского населения: новые вызовы современных технологий // Нейронаука для медицины и психологии: XVII Международный междисциплинарный конгресс. Судак, Крым, Россия; 30 мая - 10 июня 2021 г. - Москва: МАКС Пресс, 2021 - С. 406.

8. Хорсева Н.И. Марахова В.А. Дистанционное обучение: первые итоги мониторинга //Нейронаука для медицины и психологии: XVII Международный междисциплинарный конгресс. Судак, Крым, Россия 30 мая - 10 июня 2021 г.: Труды Конгресса. - Москва: МАКС Пресс, 2021 - С. 406 407

9. Хорсева Н.И., Марахова В.А., Григорьев Ю.Г. Вопросы электромагнитной безопасности цифровизации образования //Нейронаука для медицины и психологии: XVII Международный междисциплинарный 
конгресс. Судак, Крым, Россия 30 мая - 10 июня 2021 г - Москва: МАКС Пресс, - 2021 - С. $407-408$.

10. Хорсева Н.И. Мобильная связь и наши дети: ситуация требует решения // VIII Съезд по радиационным исследованиям, Москва, 12-15 окт.2021 г.- Дубна: ОИЯИ, 2021 - С. 323.

11. Хорсева Н.М., Марахова В.А. Формирование культуры пользования мобильными телефонами в образовательной среде. //VIII Съезд по радиационным исследованиям, Москва, 12-15 окт.2021 г.- Дубна: ОИЯИ, 2021 - C. 324.

12. Хорсева Н.И. Марахова В.А. Современная образовательная среда: формирование культуры пользования мобильными телефонами // Радиобиология: современные проблемы 2020 : материалы международной научной конф-нции (Гомель, 24 - 25 сентября 2020 г) Минск,2020. С.142-145.

13. Верещако, Г.Г. Влияние электромагнитного излучения мобильных телефонов на состояние мужской репродуктивной системы и потомство. Минск, - Беларуская навука - 2015. - 303с.

14. Чуешова Н.В. Репродуктивная система крыс-самцов на постнатальном этапе развития и их последующих поколений при воздействии электромагнитного излучения мобильного телефона: автореферат дисс. ... канд. биол -Минск,- 2020 - 27c.

15. Mortazavi S A R Taeb . S., Mortazavi S M J et al. The Fundamental Reasons Why Laptop Computers should not be Used on Your Lap.// J Biomed Phys Eng . 2016.-Vol.6.-№ 4.-P.279-284.

16. Старцев М.В. Дистанционное образование: а где преимущества? // Психолого-педагогический журнал «ГАУДЕАМУС».- 2020.- Т. 19. -№ 2 (44). C. 99-106.

17. Кучма, В.Р. Седова А С., Степанова М.И. и др. Особенности жизнедеятельности и самочувствия детей и подростков, дистанционно обучающихся во время эпидемии новой коронавирусной инфекции (COVID19).//Вопросы школьной и университетской медицины и здоровья.- 2020.№2.- C. 4-24.

18. Хорсева Н.И. Марахова В.А. Дистанционное обучение: первые итоги мониторинга //Нейронаука для медицины и психологии: XVII Международный междисциплинарный конгресс. Судак, Крым, Россия; 30 мая - 10 июня 2021 г.: Труды Конгресса. Москва: МАКС Пресс,- 2021. С. 406-407. 
19. Хорсева Н. И., Марахова В. А., Григорьев Ю. Г.. Дистанционное обучение: электромагнитная безопасность современного образования.// Современные проблемы радиобиологии - 2021 : материалы Международной научной конференции (23-24 сентября 2021 г., Гомель) - Минск : ИВЦ Минфина, 2021. - С.187-191.

20. Гигиенические нормативы и специальные требования к устройству, содержанию и режимам работы в условиях цифровой образовательной среды в сфере общего образования. Руководство. М.: НМИЦ здоровья детей Минздрава России, 2020 - 20 с

21. СП 2.4. 3648-20 "Санитарно- эпидемиологические требования к организациям воспитания и обучения, отдыха и оздоровления детей и молодежи"

22. СанПиН 1.2.3685-21 «Гигиенические нормативы и требования к обеспечению безопасности и (или) безвредности для человека факторов внешней среды обитания».

23. Рубцова Н.Б. Пальцев Ю.П. Состояние и перспективы обеспечения безопасности человека при использовании систем сотовой связи // Ж. Безопасность жизнедеятельности.- 2006.- №2.- С. 28-33

24. Руководство «Гигиенические нормативы и специальные требования к устройству, содержанию и режимам работы в условиях Цифровой образовательной среды в сфере общего образования», опубликованном на сайте сайте НИИ гигиены и охраны здоровья детей и подростков ФГАУ НМИЦ

25. Проект совместного документа Минпросвещения России и Минцифры России «Об утверждении стандарта «цифровая школа»»». 